\title{
Use of absolute lymphocyte count or neutrophil ingestion rate of nitroblue tetrazolium (NBT) as alternative index to CD4+T-cell count to initiate ART in the management of HIV/AIDS disease
}

\author{
N.R. UKIBE ${ }^{1 *}$, C.C. ONYENEKWE ${ }^{2}$, J.E. AHANEKU ${ }^{3}$, S.N. UKIBE ${ }^{4}$, S.C. MELUDU ${ }^{1}$, \\ A. ILIKA ${ }^{5}$, M. IFEANYICHUKWU ${ }^{6}$, M. EZEANI ${ }^{6}$ and A.O. IGWEGBE $^{7}$ \\ ${ }^{I}$ Department of Human Biochemistry, College of Health Sciences, Nnamdi Azikiwe University, Nnewi Campus, \\ P.M. B 5001 Nnewi, Anambra State, Nigeria. \\ ${ }^{2}$ Deparment of Medical Laboratory Science, College of Health Sciences, Nnamdi Azikiwe University, \\ Nnewi Campus, P.M. B 5001 Nnewi, Anambra State, Nigeria. \\ ${ }^{3}$ Department of Chemical pathology, College of Health Sciences, Nnamdi Azikiwe University, \\ Nnewi Campus, P.M. B 5001 Nnewi, Anambra State, Nigeria. \\ ${ }^{4}$ Department of Prosthesis and Orthopedic Technology, \\ School of Health Federal University of Technology Owerri. \\ ${ }^{5}$ Department of community medicine, College of Health Sciences, Nnamdi Azikiwe University, Nnewi Campus, \\ P.M. B 5001 Nnewi, Anambra State, Nigeria. \\ ${ }^{6}$ Department of immunology, College of Health Sciences, Nnamdi Azikiwe University, \\ Nnewi Campus, P.M. B 5001 Nnewi, Anambra State, Nigeria. \\ ${ }^{7}$ Department of Obstetrics and Gynecology, College of Health Sciences, Nnamdi Azikiwe University, \\ Nnewi Campus, P.M. B 5001 Nnewi, Anambra State, Nigeria. \\ *Corresponding author, E- mail: ezinne4real2007@yahoo.com
}

\begin{abstract}
The present study was designed to evaluate absolute lymphocyte count or neutrophil ingestion rate of NBT as alternative indices to $\mathrm{CD}^{+} \mathrm{T}$ cell count in the management of HIV/AIDS subjects. 158 adult participants (male $=70$, female $=88$ ) were recruited for the study and grouped as: (i) Symptomatic HIV subjects with or without malaria (ii) Asymptomatic HIV subjects (iii) HIV seronegative subjects with or without malaria. Blood samples taken from these participants were analyzed using standard procedures for absolute lymphocyte count, neutrophil ingestion rate of NBT and CD4+ T cell count. The result showed that the mean absolute lymphocyte and neutrophil ingestion rate of NBT were significantly reduced in both symptomatic and asymptomatic HIV subjects with or without malaria infection when compared to the control group. The CD4+ T cell count was significantly reduced in the two groups and positively correlated with the absolute lymphocyte count $(\mathrm{r}=0.301, \mathrm{P}<0.05, \mathrm{r}=0.403, \mathrm{P}<0.05)$ and neutrophil ingestion rate of NBT $(\mathrm{r}=$ $0.116, \mathrm{P}=0.01, \mathrm{r}=0.359, \mathrm{P}<0.01)$ with or without malaria infection respectively. This finding suggests that in resource limited settings, absolute lymphocyte count or neutrophil ingestion rate of NBT could be used as alternative to CD4 count to monitor or initiate ART where the later is not easily accessible especially in a malaria endemic area.
\end{abstract}

(c) 2012 International Formulae Group. All rights reserved.

Keywords: Absolute lymphocyte count, NBT, ART, CD4+ T-cell count, HIV 


\section{INTRODUCTION}

The emergence of HIV in the early eighties brought with it the need to find effective control measures so as to check the spread of the virus and reduce the high morbidity and mortality associated with it especially in sub-Saharan Africa where malaria has interacted with it to bring a worse situation. Whereas heterosexual mode of transmission is the commonest way of transmission (UNAIDS, 2004), malaria spread takes place all the year round by the bite of female anopheles mosquitoes and the prevalence has been reported to be triple in subjects with symptomatic HIV diseases (Onyenekwe et al., 2007).

The discovery of antiretroviral drugs (ART) as an effective means of HIV/AIDS control brought with it some challenges including when and how to introduce the drugs in the face of scarce resources especially in the developing poor countries of the world where the burden of HIV/AIDS and malaria is very high (UNAIDS, 2004). CD4 ${ }^{+}$ $\mathrm{T}$ cell count was the primary index used to initiate ART in infected individuals (FHI, 2005). However, situations arise especially in some developing countries when there are no facilities to measure CD4+ T- cell counts or the CD4+ T-cell count itself has not fallen below $200 / \mathrm{mm}^{3}$ in a subject whose clinical condition has deteriorated and obviously requires the introduction of ART. The need therefore arises for another blood parameter to be developed for use as an alternative index for monitoring and initiation of ART in HIV/AIDS subjects. The neutrophil ingestion rate of NBT or absolute lymphocyte count can serve as alternatives since these parameters can easily be estimated without requiring complex technology which is necessary in CD4+ T-cell count estimation.

We have previously reported a significant difference in the rate of NBT reduction in symptomatic and asymptomatic HIV infected subjects, irrespective of their malaria parasite status (Onyenekwe et al., 2008). Also, the Family Health international in Nigeria has advocated for the use of total lymphocyte count of 1000 cells $/ \mathrm{mm}^{3}$ as minimum baseline for ART initiation, where CD4+ count is not easily available (FHI, 2005). However, Kamya et al (2004) reported that total lymphocyte count of 1200 was not a sensitive predictor of CD4 lymphocyte count among patients with HIV disease in Kampala Uganda. In the same report, the authors noted a strong correlation between total lymphocyte count and CD4 with a very high positive predictive value for a CD4 less than 200 cells $/ \mathrm{mm}^{3}$. The negative predictive value was however, very low showing that using the WHO recommendation of total lymphocyte cut off of 1200 (WHO, 2002), majority of WHO stage 2 and 3 patients with CD4 less than 200 cells $/ \mathrm{mm}^{3}$ will not be identified and will therefore not be treated.

The present study therefore seeks to evaluate neutrophil ingestion rate of NBT or absolute lymphocyte counts as possible alternative indices for monitoring and initiation of ART in $3^{\text {rd }}$ world countries where facilities are limited, since these parameters have been found to be severely affected in HIV/AIDS subjects (Blatt et al., 1993; Beck et al., 1996; Onyenekwe et al., 2008) especially when there is malaria co-infection.

\section{MATERIALS AND METHODS}

\section{Subjects}

One hundred and fifty-eight participants (males $=70$, females $=88$ ) aged between 16 and 72 years recruited at the voluntary and counseling unit (VCT) and HIV laboratory unit of Nnamdi Azikiwe University Teaching Hospital Nnewi, South Eastern Nigeria participated in the study. The study was carried out during the rainy season when malaria transmission was at its peak between June and August. All the participants were subjected to double HIV screening malaria parasite screening. The participants were grouped based on WHO guidelines for HIV staging as

(i). Symptomatic HIV subjects $(\mathrm{n}=68) .33$ participants had $P$. falciparum malaria.

These participants were categorized as HIV stage 2 . 
(ii). Asymptomatic HIV subjects $(\mathrm{n}=$ 50). 20 of these participants had malaria parasite infection. They were categorized as HIV stage 1.

(iii). HIV seronegative subjects $(n=40) .20$ of these participants had malaria parasite infection. They were regarded as the control subjects.

Blood sample collected from the entire participants were used to determine CD4+ T cell count, absolute lymphocyte count, blood phagocyte ingestion rate of NBT and absolute neutrophil count. The neutrophil population in blood of participants was used to adjust the number of neutrophils per $\mathrm{ml}$ of blood to $1 \times 10^{6}$. The participants gave informed consent and the Ethical Committee of Nnamdi Azikiwe University Teaching Hospital approved the study design.

\section{Determination of HIV1 and HIV2 Antibodies}

Two different methods were used namely Abbott Determine HIV 1 \& 2 kit which is an in vitro visually read immunoassay (Abbot Japan Co. Ltd. Tokyo, Japan) and HIV 1 \& 2 STAT-PAK Assay kit, which is an immunochromatographic test for the qualitative detection of antibodies to HIV 1 and HIV 2 in human plasma (CHEMBIO Diagnostic System, INC, New York, USA). Abbott determines HIV $1 \&$ 2: The procedure was as described by the manufacturers of the kit (Abbot Japan Co. Ltd. Tokyo, Japan). 50 $\mu l$ of participants' plasma samples separated from corresponding whole blood samples in EDTA were dispensed into the appropriately labeled "specimen pad" of the test strip. The reaction was allowed for 15 minutes, and then the results were read. This method has inherent quality control that validates the results. The appearance of distinct red lines at the test region and control region of the kit suggest positive HIV test while one distinct red line in the control region suggest HIV seronegative test.

STAT-PAK immunochromatographic method for HIV 1 \& 2: This kit was used as a point of care test. The procedure was as described by the manufacturers of the kit. $5 \mu \mathrm{l}$ of participant's plasma were dispensed into the sample wells; buffer supplied by the manufacturer was added drop-wise into the appropriately labeled sample wells. The results of the tests were read at 10 minutes after the addition of the running buffer. This method has inherent quality control that validates the results. HIV seropositive results' using these two methods was used to classify participants as presenting with HIV infection.

\section{Diagnosis of $\boldsymbol{P}$. falciparum malaria}

Whole Blood was used for the diagnosis of $P$. falciparum malaria using Malaria Plasmodium falciparum Rapid Test Device (Para check, Orchid Biomedical systems, Vena Goa, India) and Giemsa stained thick blood smears for microscopic detection of $P$. falciparum parasites. The parasites density was determined as previously reported (Dacie et al., 1984) and density expressed per liter of blood. However the principle of $P$. falciparum antigen detection is based on a rapid chromatographic immunoassay for the qualitative detection of circulating $P$. falciparum antigen in the whole blood. This method utilizes gold conjugate to selectively detect plasmodium antigen. The procedure was as described by the manufacturer. $10 \mathrm{ul}$ of whole blood specimen from the participants were dispensed into well labeled specimen cassettes containing sample well. Subsequently, 3 drops of buffer supplied by the manufacturer approximately $120 \mu \mathrm{l}$ was added into the sample wells. After 15 minutes the results were read. The test device has inherent quality control that validates the result. The presence of two pink lines at the region of the control and test sample signifies presence of $P$. falciparum malaria infection while the presence of only 1 pink line in the control region signifies absence of $P$. falciparum malaria.

\section{Determination of $\mathrm{CD4}^{+}$T-cells count by Cyflow SL Green}

About $50 \mu \mathrm{l}$ of whole blood in EDTA anti-coagulant was dispensed into a partec test 
tube and $10 \mathrm{ml}$ of CD4 PE antibody was added. The reaction mixture was incubated in the dark for 15 mins. After the incubation, 800 $\mu \mathrm{l}$ of the already prepared diluted buffer was dispensed into each reaction tube and vortexed. The partec tubes containing these reactions were plugged in position in the cyflow SL Green (Partec, Germany), which has already been connected to flow max software. CD4 count template data file and CD4 count instrument. The test was run on the cyflow for $90 \mathrm{sec}$. The results were displayed as histogram and printed. The $\mathrm{CD}^{+} \mathrm{T}$ cell count was read off the histogram correcting for the dilution factor.

\section{Determination of absolute neutrophil count}

The absolute neutrophil and absolute lymphocyte counts were obtained by total white blood cell count value multiplied by the percent blood neutrophil and lymphocyte differential counts as described by Dacie and Lewis (1984).

Neutrophil Phagocyte Function Test Using Nitro-blue Tetrazolium (NBT) Ingestion Rate as Described by Hudson and Hay (1993)

Total white blood cell count and differential white cell count was enumerated for each sample. The absolute neutrophil count was evaluated and the quantity of blood in $\mathrm{ml}$ that contained $1 \times 10^{6}$ neutrophil in $\mathrm{ml}$ of blood was calculated in each sample. The quantity of blood in $\mathrm{ml}$ that contained 1 million neutrophil (in each sample) was dispensed into test tubes. $0.1 \mathrm{ml}$ of freshly prepared 4-mmol NBT solutions was dispensed into the tubes and the contents of the tubes were mixed and incubated at $37{ }^{\circ} \mathrm{C}$ for 20 minutes. After incubation, $5 \mathrm{ml}$ of dioxan was dispensed into the tubes and the tubes incubated at $70{ }^{\circ} \mathrm{C}$ for 20 minutes with occasional vigorous shaking. A blue-brown colour developed and dioxan extract was separated by centrifugation at $4000 \mathrm{~g}$ for 10 minutes at room temperature. The extract was measured at $520 \mathrm{~nm}$ using spectrophotometer. The absorbance was multiplied by a factor 40.3.

\section{Determination of conversion factor}

A quantity of 150 umol ascorbic acid was dispensed into a tube containing $0.2 \mathrm{ml}$ of $4 \mathrm{mMol}$ NBT solutions and mixed thoroughly. $2 \mathrm{ml} 0.1 \mathrm{M}$ sodium hydroxide in $24 \mathrm{mMol}$ sodium bicarbonate solution was dispensed into the reaction mixture and incubated at room temperature for 10 minutes. $4 \mathrm{ml}$ of dioxan was added and the mixture was thoroughly shaken. Subsequently, 1:10 dilution of this suspension was made in dioxan and incubated at $70{ }^{\circ} \mathrm{C}$ for 20 minutes. This was cooled at room temperature and the absorbance measured at $520 \mathrm{~nm}$ using spectrophotometer. Dioxan was used as blank. The conversion factor was derived to be 4.3 .

\section{Statistical Analysis}

The variables were expressed as mean (+SD). The Independent student $\mathrm{T}$ test was used to assess for significant mean differences, Spearman's correlation coefficient was used to assess the level of association between two variables. Significant levels was considered at $\mathrm{P}<0.05$.

\section{RESULTS}

There was no significant difference observed in CD4+ $\mathrm{T}$ cell count, formazan generated per neutrophil, absolute lymphocyte count and absolute neutrophil count between the symptomatic and asymptomatic HIV subjects with or without malaria $(\mathrm{P}>0.1)$ respectively. Similar observation was made between the asymptomatic HIV and the control counterparts. CD4+ $\mathrm{T}$ cell and formazan generated per neutrophil were more reduced in symptomatic and asymptomatic HIV subjects with or without malaria compared to their corresponding control subjects (Table 1).

When the Between group comparison were made, a significant difference were observed in the mean $( \pm \mathrm{SD}) \mathrm{CD} 4+\mathrm{T}$ cell, absolute lymphocyte count, formazan generated per neutrophil between the symptomatic HIV with malaria and the corresponding control $(\mathrm{p}<0.01)$. Similar observation was made in absolute neutrophil 
count within the same group $(\mathrm{P}<0.05)$. A significant difference were observed in the mean $( \pm \mathrm{SD}) \mathrm{CD} 4+\mathrm{T}$ cell and formazan generated per neutrophil when the asymptomatic HIV subjects with malaria was compared with the control $(\mathrm{P}<0.01)$. Conversely, there were no significant difference observed in the mean $( \pm \mathrm{SD})$ absolute lymphocyte and absolute neutrophil count in the same group of subjects $(\mathrm{P}>0.05)$. Similarly, no significant difference was observed in the mean $( \pm \mathrm{SD}) \mathrm{CD} 4+\mathrm{T}$ cell count, formazan generated per neutrophil, absolute lymphocyte count and absolute neutrophil count between the symptomatic HIV and asymptomatic HIV subjects with malaria $(\mathrm{P}>0.05)$ respectively (Table 2$)$.

There was a significant reduction in the mean $( \pm \mathrm{SD}) \mathrm{CD}^{+} \mathrm{T}$-cell count, formazan generated per neutrophil, absolute lymphocyte count and absolute neutrophil count between the symptomatic HIV subjects without malaria and the corresponding control $(\mathrm{P}<0.05,<0.01$, $<0.01,<0.05)$ respectively. No significant difference was observed in the mean $( \pm \mathrm{SD})$ absolute lymphocyte count and absolute neutrophil count between the asymptomatic HIV subjects without malaria and the control counterpart $\quad(\mathrm{P}>0.05)$ Conversely, a significant difference was observed in the mean $( \pm \mathrm{SD}) \mathrm{CD}^{+} \mathrm{T}$ cell count, formazan generated per neutrophil between the asymptomatic HIV subjects without malaria and the corresponding control $(\mathrm{P}<0.05)$. Similar observation was made in the mean $( \pm \mathrm{SD}) \mathrm{CD}^{+} \mathrm{T}$ cell count between symptomatic HIV and asymptomatic HIV subjects without malaria $(\mathrm{P}<0.05)$. On the other hand, no significant difference was observed in the mean $( \pm \mathrm{SD})$ absolute lymphocyte count, formazan generated per neutrophil and absolute neutrophil count between the symptomatic and asymptomatic HIV subjects without malaria.

Table 1: Comparison of mean $( \pm \mathrm{SD})$ formazan, absolute lymphocyte count, absolute neutrophil count and CD4+ T cell count in symptomatic, asymptomatic HIV and control subjects with or without malaria.

\begin{tabular}{lcccc}
\hline Parameters & $\begin{array}{c}\text { Absolute } \\
\text { lymphocyte } \\
\left(\mathbf{~ m m}^{\mathbf{3}}\right)\end{array}$ & $\begin{array}{c}\text { Formazan } \\
(\mathbf{F m o l} / \mathbf{p h a g})\end{array}$ & $\begin{array}{c}\text { CD4+ } \\
\mathbf{c o u n t} \\
\left(\mathbf{m m}^{\mathbf{3}}\right)\end{array}$ & $\begin{array}{c}\text { Absolute } \\
\text { neutrophil } \\
\left(\mathbf{x 1 0}^{\mathbf{6}}\right)\end{array}$ \\
\hline Symptomatic HIV with malaria & $1.31 \pm 0.70$ & $17.99 \pm 7.00$ & $274 \pm 178$ & $1.49 \pm 0.55$ \\
Symptomatic HIV without malaria & $1.71 \pm 0.64$ & $19.25 \pm 3.79$ & $238 \pm 176$ & $2.00 \pm 0.96$ \\
P - value & $>0.05(\mathrm{~ns})$ & $>0.05(\mathrm{~ns})$ & $>0.05(\mathrm{~ns})$ & $>0.05(\mathrm{~ns})$ \\
Asymptomatic HIV with malaria & $2.03 \pm 1.29$ & $18.13 \pm 4.70$ & $312 \pm 144$ & $2.04 \pm 0.76$ \\
Asymptomatic HIV without malaria & $2.15 \pm 0.80$ & $20.02 \pm 6.53$ & $403 \pm 226$ & $2.20 \pm 0.89$ \\
P - value & $>0.05(\mathrm{~ns})$ & $>0.05(\mathrm{~ns})$ & $>0.05(\mathrm{~ns})$ & $>0.05(\mathrm{~ns})$ \\
& & & & \\
Control with malaria & $2.25 \pm 0.84$ & $29.36 \pm 5.25$ & $504 \pm 181$ & $2.88 \pm 1.45$ \\
Control without malaria & $2.30 \pm 1.08$ & $27.22 \pm 7.79$ & $518 \pm 237$ & $2.94 \pm 1.52$ \\
P - value & $>0.1(\mathrm{~ns})$ & $>0.1(\mathrm{~ns})$ & $>0.1(\mathrm{~ns})$ & $>0.1(\mathrm{~ns})$ \\
\hline$\quad$ Key: ns = not significant & & & &
\end{tabular}


Table 2: Between group comparison of mean $( \pm \mathrm{SD})$ absolute lymphocyte count, formazan, absolute neutrophil count and CD4+ T cell count in symptomatic, asymptomatic HIV and control subjects with malaria.

\begin{tabular}{lcccc}
\hline Parameters & $\begin{array}{c}\text { Absolute } \\
\text { lymphocyte } \\
\left(\mathbf{/ m m}^{\mathbf{3}}\right)\end{array}$ & $\begin{array}{c}\text { Formazan } \\
(\text { Fmol/phag }\end{array}$ & $\begin{array}{c}\mathbf{C D}^{+} \\
\mathbf{c o u n t}^{+} \\
\left(/ \mathbf{m m}^{\mathbf{3}}\right)\end{array}$ & $\begin{array}{c}\text { Absolute } \\
\text { neutrophil } \\
\left(\mathbf{x 1 0}^{\mathbf{6}}\right)\end{array}$ \\
\hline Control with malaria & $2.25 \pm 0.84$ & $29.36 \pm 5.25$ & $504 \pm 181$ & $2.88 \pm 1.45$ \\
Symptomatic HIV with malaria & $1.31 \pm 0.70$ & $17.99 \pm 7.00$ & $247 \pm 178$ & $1.49 \pm 0.55$ \\
P - value & $<0.01$ & $<0.01$ & $<0.01$ & $<0.05$ \\
& & & & \\
Control with malaria & $2.25 \pm 0.84$ & $29.36 \pm 5.25$ & $504 \pm 181$ & $2.88 \pm 1.45$ \\
Asymptomatic HIV with malaria & $2.03 \pm 1.29$ & $18.13 \pm 4.70$ & $312 \pm 144$ & $2.04 \pm 0.76$ \\
P - value & $>0.05(\mathrm{~ns})$ & $<0.01$ & $<0.01$ & $>0.05(\mathrm{~ns})$ \\
& & & & \\
Symptomatic HIV with malaria & $1.31 \pm 0.70$ & $17.99 \pm 7.00$ & $247 \pm 178$ & $1.49 \pm 0.55$ \\
Asymptomatic HIV with malaria & $2.03 \pm 1.29$ & $18.13 \pm 4.70$ & $312 \pm 144$ & $2.04 \pm 0.76$ \\
P - value & $>0.05(\mathrm{~ns}$ & $>0.05(\mathrm{~ns})$ & $>0.05(\mathrm{~ns})$ & $>0.05(\mathrm{~ns})$ \\
\hline Key: ns = not significant & & & &
\end{tabular}

Key: $\mathrm{ns}=$ not significant

Table 3: Between group comparison of mean $( \pm \mathrm{SD})$ absolute lymphocyte count, formazan, absolute neutrophil count and CD4+ T cell count in symptomatic, asymptomatic HIV and control subjects without malaria.

\begin{tabular}{|c|c|c|c|c|}
\hline Parameters & $\begin{array}{c}\text { Absolute } \\
\text { lymphocyte } \\
\left(/ \mathbf{m m}^{3}\right)\end{array}$ & $\begin{array}{c}\text { Formazan } \\
\text { (Fmol/phag }\end{array}$ & $\begin{array}{c}\mathrm{CD4}^{+} \mathrm{T} \\
\text { cell count } \\
\left(/ \mathrm{mm}^{3}\right)\end{array}$ & $\begin{array}{c}\text { Absolute } \\
\text { neutrophil } \\
\left(\mathbf{x 1 0}^{6}\right)\end{array}$ \\
\hline Control without malaria & $2.30 \pm 1.08$ & $27.22 \pm 7.79$ & $518 \pm 237$ & $2.94 \pm 1.52$ \\
\hline Symptomatic HIV without malaria & $1.71 \pm 0.64$ & $19.25 \pm 3.79$ & $238 \pm 176$ & $2.00 \pm 0.96$ \\
\hline $\mathrm{P}$ - value & $<0.05$ & $<0.01$ & $<0.01$ & $<0.05$ \\
\hline Control without malaria & $2.30 \pm 1.08$ & $27.22 \pm 7.79$ & $518 \pm 237$ & $2.94 \pm 1.52$ \\
\hline Asymptomatic HIV without malaria & $2.15 \pm 0.80$ & $20.02 \pm 6.53$ & $403 \pm 226$ & $2.20 \pm 0.89$ \\
\hline$P$ - value & $>0.05(\mathrm{~ns})$ & $<0.05$ & $<0.05$ & $>0.05(\mathrm{~ns})$ \\
\hline Symptomatic HIV without malaria & $1.71 \pm 0.64$ & $19.25 \pm 3.79$ & $238 \pm 176$ & $2.00 \pm 0.96$ \\
\hline Asymptomatic HIV without malaria & $2.15 \pm 0.80$ & $20.02 \pm 6.53$ & $403 \pm 226$ & $2.20 \pm 0.89$ \\
\hline$P$ - value & $>0.05(\mathrm{~ns})$ & $>0.05(\mathrm{~ns})$ & $<0.05$ & $>0.05(\mathrm{~ns})$ \\
\hline
\end{tabular}

\section{DISCUSSION}

The present study showed that the absolute lymphocyte count was significantly reduced in HIV infected subjects when compared with the normal control subjects. The degree of reduction was more marked in symptomatic HIV subjects than in asymptomatic ones. Malaria infected HIV subjects had a more significant reduced absolute lymphocyte count when compared with the corresponding control group with malaria. This suggests an impact of malaria on absolute lymphocyte count. Similarly, the mean CD4+ T cell count was significantly 
reduced in the corresponding groups studied when compared to the normal control subjects. The degree of reduction was more marked in symptomatic HIV subjects than in the asymptomatic ones indicating that the CD4+ $\mathrm{T}$ cells became more depleted as progression to AIDS occurred. It should be recalled that the $\mathrm{T}$ lymphocytes are the primary effector cells responsible for clearing the HIV virus from the system at the early stage of the infection and also fighting opportunistic infections, which results as the condition progresses. Subsequently, many of the CD4+ T cells get killed during the course of this response resulting to the number being depleted. It should also be recalled that CD4+T cells are components of the absolute lymphocyte count, and once depleted, the later will invariably fall in number. Thus, there is a direct proportional relationship between absolute lymphocyte count and CD4+ T cell count. Previous reports (French et al., 2001; Desta et al., 2006) of low CD4+ T cell counts in subjects with severe malaria have been documented and the situation is bound to get worse in HIV infection when malaria seem to be worse. Absolute lymphocyte count could therefore substitute CD4+ $\mathrm{T}$ cell count in resource-limited settings where facility does not exist for the determination of the later. Furthermore, the positive correlation observed between CD4+ $\mathrm{T}$ cell count and absolute lymphocyte count suggests that the two parameters are interchangeable, hence absolute lymphocyte count could be adapted as an alternative parameter for deciding eligibility of HIV subjects to monitor or initiate ART by the Global agency for HIV/AIDS in Nigeria (GHAIN) (FHI,2005). Reports of previous studies (Akanmu et al., 2001; Arthur \& Burrowes, 2006) support the use of absolute lymphocyte as an alternative marker of immunity in HIV subjects.

Similarly, the neutrophil ingestion rate of NBT in HIV infected subjects was significantly reduced when compared to the normal control subjects. This implies grossly reduced absolute neutrophil count and neutrophil phagocytic function. The degree of reduction was more marked in symptomatic ones. Malaria infection seemed to have negative impact on absolute neutrophil count in symptomatic subjects than the asymptomatic ones. Like CD4+T-cells, neutrophils are the body's chief effector cells performing phagocytic functions to rid the body of invading organisms including parasites. Thus, they are responsible for eliminating bacterial, fungal protozoal or other parasitic organisms that are responsible for the opportunistic infections, which are common in HIV disease. With greater disease progression, the number of neutrophil (like CD4+ $\mathrm{T}$ cells), get fewer and fewer in circulation and cellular immunity continues to fall. If the absolute neutrophil count falls below 200 cells/ul, inflammatory response might become non-existent (Brooks et al., 2005). Prolonged use of highly active antiretroviral therapy (HAART) has been associated with this phenomenon (Brooks et al., 2005) probably as a result of bone marrow suppressive effect of the component drugs. Reports of reduced neutrophil counts and hence phagocytic function in HIV infected subjects have been previously documented (Brooks et al., 2005; Arthur et al., 2006; Onyenekwe et al., 2008). Neutrophil dysfunction has been found to depend on the stage of HIV/AIDS and the CD4+ T cell count in extreme cases of low CD4+ T cell counts, $(<100 / \mathrm{ll})$, neutrophil phagocytic function become extremely low (Grimwade et al., 2004; Cohen et al., 2005; Anyiwo et al., 2006). The positive correlation observed between CD4+T-cell count and neutrophil ingestion rate of NBT (absolute neutrophil count or neutrophil phagocytic function) in the present study therefore suggest that the two parameters can substitute each other in areas where it is more feasible to determine one in preference to the other.

The development of a reliable parameter other than CD4+ T cell count to be used to decide eligibility to initiate ART has become overdue especially in developing countries where there is mass poverty and frequent power failures to run complicated 
machines. This will go a long way to alleviate the problems associated with the diagnosis and treatments of HIV/AIDS disease thus unnecessary delays in the initiation of ART will be avoided. The public health implication of this cannot be overemphasized.

\section{Conclusion}

In conclusion, Absolute lymphocyte count and Neutrophil Ingestion rate of Nitroblue Tetrazolium are positively correlated with CD4+ T cell count in patients with HIV/AIDS disease in Nnewi, Nigeria. It is suggested that in resource constrained areas such as the $3^{\text {rd }}$ world countries, these parameters (absolute lymphocyte and Neutrophil ingestion rate of NBT) could be used as alternative indices to $\mathrm{CD} 4+\mathrm{T}$ cell count to initiate ART and monitor progress in the management of patients with HIV/AIDS disease.

\section{ACKNOWLEDGMENTS}

The authors sincerely wish to acknowledge the staff of the VCT unit, HIV laboratory unit of Nnamdi Azikiwe University Teaching Hospital Nnewi and the staff and management of Awka South Local Government Area, Anambra State, Nigeria.

\section{REFERENCES:}

Akanmu AS, Akinsele I, Eshofonie AO, Davies AO, Okany CC. 2001. Absolute lymphocyte count as surrogate for CD4+ cell count in monitoring responses to antiretroviral therapy. Niger Postgrad Med J., 8(3): 105-111.

Anyiwo CE, Okerengwo AA. 2006. Essentials Immunology for Students of Medicine and Allied Subjects. Pearl Publishers; 157-163.

Arthur A, Sahai B, Mald. 2006. Use of Total Lymphocyte Counts Vs. CD4+T-cell count as a marker of immunity in HIVInfected Adults and Children Global Strategies for HIV Prevention. http://www.womenchildrenhiv.org/wchiv ? Page=lp-02-03.
Beck EJKE, Gompels MM, Pinching AJ. 1996. Correlation between total and CD4 lymphocyte counts in HIV infection: not making the good an enemy of the not so perfect. International J. of STD \& AIDS, 7(7): 422-428.

Blatt SP, Lucey CR, Butzin CA, Hendrix CW, Lucey DR. 1993. Total lymphocyte count as a predictor of absolute CD4+ count and CD4+ percentage in HIV-Infected persons. JAMA., 269(5): 622-626.

Brooks JT, Masoba TR, Amornkul P, Mwaengo D, Valule J, Fowler M, Slutsker L, Decock K. 2005. Neutropenia in HIV infected Kenyan Women Receiving ART to prevent mother- tochild HIV transmission Con. Retroviral Opportunistic infect., 22 (12): 817.

Chirenda J, Siziya S, Tshimanga M. 2000. Association of HIV Infection with the development of severe and complicated malaria cases at rural hospital in Zimbabwe. Cent. Afr. J. Med., 46: 5-9.

Cohen C, karastaedt A, Frean J, Thomas J, Go vender N. 2005. Increased Prevalence of severe malaria in HIV infected adults in South Africa. Clin. Infect. Dis., 41(11): 1631-1637.

Dacie JV, Lewis S.M. 1984. Practical Haematology $\quad\left(6^{\text {th }}\right.$ edn $) . \quad$ Churchill Livingstone: Edinburgh.

Delta K, Beyene P, Tsehaynesh M, Ermias H. 2006. Characterization of peripheral blood lymphocytes-subsets in Acute Plasmodium falciparum and P.vivax malaria infections in sugar estate. Ethiopia. J. Clin. Vaccine Immuno., 13(3): 376-379.

Family Health International. 2005. Federal Ministry of Health Eligibility Criteria for Antiretroviral Drugs National Guidelines on Antiretroviral Therapy, Nigeria.

French N, Nakiingi J, Luganda E, Watera C, Whitwort JA, Gilks CF. 2001. Increasing rates of malaria fever with deteriorating immune and acute febrile episodes in Uganda adults: a case control study. AIDS, 15: 2445-2450. 
Grimwade K, French N, Mbatha DD, Dedicoat M, Gilks CF. 2004. HIV Infection as a co-factor for severe falciparum malaria in adults living in a region of unstable malaria transmission in South Africa. AIDS, 18(3): 547-554.

Hudson L, Hay FC. 1993. Practical Immunology ( $3^{\text {rd }}$ edn). Blackwell Scientific Publication.

Kamya MR, Semitala FC, Quinn TC, Ronald A, Njama- Meya D, Mayanja-Kizza H, Katabira, ET, Spacek LA. 2004. Total lymphocyte count of 1200 is not a sensitive predictor of CD4 lymphocyte count among patients with HIV disease in Kampala, Uganda. Afr. Health Sci., 4(2): 94-101.

Luafer MK, Van Oosterhout JJ, Thesing PC, Thumba F, Zijlstra EE, Graham SM, Taylor TE, Plowe CV. 2006. Impact of HIV associated immunosuppression on Malaria Infection and Disease in Malawi. J. Infection Dis., 193: 872-8.

Onyenekwe CC, Ukibe NR, Meludu SC, Ilika A, Aboh N, Ofiaeli N, Ezeani MO, Onochie MA. 2007. Prevalence of malaria as co-infection in HIV infected individuals in a malaria endemic area of South Eastern Nigeria. J. Vector Borne Dis., 44: 250-254.

Onyenekwe CC, Ukibe NR, Meludu SC, Igwegbe AO, Ifeanyi MI, Ezeugwunne I Ezeani M, Onochie A, Ofiaeli N, Aboh N, Ilika A. 2008. Neutrophil Ingestion Rate of Nitroblue Tetrazolium in subjects with Malaria-HIV Co-Morbidity. Tropical journal of medical research, 12: 1.

Partnaik P, Jere CS, Miller WC, Hoffman IF, Wirima J, Pendame R, Mesh nick SR, Taylor TE, Molyneux ME, Kublin JG. 2005. Effects of HIV-1 serostatus, HIVRNA concentration and CD4+ Cell count on the incidence of Malaria infection in cohort study of Adult in rural Malawi. $J$. infect. Dis., 192: 984-91.

UNAIDS (Joint United Nations Programme on HIV/AIDS). 2004. AIDS epidemic Update; UNAIDS, Geneva.

WHO, Author. 2002. Scaling up Antiretroviral Therapy in Resource Limited Settings: Guidelines for a Public Health Approach. Geneva. 